\title{
A resistance model of electronic medical records adoption in Taiwanese hospitals:A multi-method approach
}

\author{
Hsin Hsin Chang ${ }^{1 *}$, Kit Hong Wong ${ }^{1}$ and Cheng Joo Eng ${ }^{2}$ \\ ${ }^{1}$ Department of Business Administration, National Cheng Kung University, Taiwan \\ ${ }^{2}$ Department of Child Educare, Min-Hwei Junior College of Health Care Management, Taiwan
}

The EMR adoption work in Taiwanese hospitals is led by the Ministry of Health and Welfare (MOHW). According to van Velthoven et al. (2016) [1], all large medical centers ( $>1,000$ beds), approximately $70 \%$ of regional hospitals and almost $30 \%$ of district hospitals use an EMR system to date. The highEMR adoption rate can be attributed to the Taiwanese National Health Insurance scheme (NHIs) [2]. There are $80 \%$ of the hospital incomes from the Bureau of National Health Insurance, and 20\% from the registration fees [3]. Due to this reason, the adoption of EMRs is considered as one of the essential requirements to link the network with the NHI system for claiming patient consultation fees and medical expensesin daily operation.

EMR is a longitudinal electronic record of patient health information generated by one or more encounters in a care delivery setting [4]; therefore, healthcare professionals' contribution plays an essential role in the process of EMR adoption. However, following financial issues and technical issues (e.g., hardly find an adequate system), the healthcare professionals' resistance, one of the human-related factors, is also a key barrier to the success of EMR adoption [5,6]. The reasons of healthcare professional resistance to the EMR adoption not onlyinclude workload increase with no extra compensation, anxiety to IT, lack of time or ability to learn new IT, inertia to the change and etc., but unjust management practices in work and information distribution also play an important part. Thus, two research questions guide this paper: (1) what are the issues that lead to healthcare professionals' resistance to the adoption of EMR system; (2) what are the elements that a hospital needs to consider to mitigate the resistance behavior?

We attempt to address the issue by adopting equity theory and psychological reactance theory to discuss the situation of healthcare professional resistance to EMR adoption in the hospital. Equity theory claims that equality of the management practice is critical to maintainemployer-employee relationships [7]. Inequality treatment often causes unfavorable feelings; therefore, we firstly adopt the concept of perceived unmet promise [8,9], which focuses on the equality of reciprocal obligations between the hospital and its employees, and four key aspects (individual, system, organization, and process) will be evaluated. Secondly, organizational justice [10] is also adopted to evaluate the hospital practice in equality of distributive, procedural, interpersonal, and informational justice. Besides, psychological reactance theory suggests that one unfavorable feeling will result in negative behaviors such as resistance behaviors [11]. Wetherefore infer that healthcare professionals expect to be treated equally when adopting the EMRs to the working place.If the hospital fails to do so, an unfavorable perception will be generated, such as perceived contract breach (PCB), leading to resistance behaviors to the EMR adoption work. Moreover, Rivard and Lapointe [12] mentioned that the resistance behavior of adopting IT in enterprises can be mitigated, and it depends on how the organization reacts to the resistance behavior. Chen and $\mathrm{Wu}$ [13] argued that high healthcare information technology (HIT) management competency can lead to effective use of IT at work. Therefore, hospital responses including inaction, acknowledgement, rectification, and dissuasion [12] as well as healthcare technology management (HTM) competency [14] are proposed to be the key elements to mitigatehealthcare professionals' resistance behaviorsto EMR adoption.

We adopted both quantitative and quantitative research approaches; the qualitative approach was to verify the reliability of each constructs, dimensions, and measurement statements in practice; senior healthcare professionals who have ever held the post of the department chief, team leader, supervisor, committee, or person incharge of the system were contacted for an in-depth interview. The quantitative approach was to empirically test the research model. A pool of field survey questionnaireitems were developed; each was measured by seven-point Likert scale ranging from 1 'strongly disagree' to 7 'strongly agree'. The objects eligible for the pilot test and the formal field survey are healthcare professionals (including doctors, nurses, healthcare staffs, medical record system technicians, healthcare IT staffs, and etc.) who have ever used medical record system in daily work. A total of 489 valid questionnaires were collected for empirical testing. PLS techniques were adopted for data analysis and hypotheses testing.

The results demonstrated thatPCB had direct effect on resistance to EMR adoption; perceived unmet promises and organizational justice not only affected healthcare professionals' PCB directly and significantly, but also had direct relation with resistance to EMRadoption. In terms of the moderating effect, acknowledgement and rectification responses can mitigatethe resistance behavior; highor low HTM competency of the group had significant differences on the effect of perceived unmet promises and organizational justice to $\mathrm{PCB}$. The $R$-square $\left(R^{2}\right)$ of perceived contract breach and resistance to EMR adoption revealed $44.9 \%$ and $54.9 \%$, indicating the predictors accounted for high variation in both models.

As the EMR system adoption is considered as a long-term

Correspondence to: Hsin Hsin Chang, Distinguished Professor of IT and Management, Department of Business Administration, National Cheng Kung University 1, University Rd, Tainan City 70101, Taiwan, Tel: 06-2757575, E-mail: easyhhc@mail.ncku.edu.tw

Received: June 05, 2017; Accepted: June 24, 2017; Published: June 26, 2017 
development for the hospital, the study suggests hospitals show initiative and provide helps to healthcare professionals for the adoption work to encourage their contribution. Moreover, justice treatment in practice is also a critical element to motivate healthcare professionals to participate in the adoption work voluntarily and initially. Hospitals are highly suggested to manage a just distribution of work responsibility, and to avoid assigning overloaded work to the healthcare professionals who have better ability and are more willing to coordinate with the hospital. Otherwise, it may cause negative emotions and increase resistance behaviors.

To develop a two-way communication mechanism is extremely important; hospitals are suggested to adopt multi-collection method, such as through review / troubleshooting meeting, formal / informal interview, questionnaire, or write-in message, to gather healthcare professionals' opinions and suggestions. Also, hospitals must respond to all feedbacks from healthcare professionals as soon as possible no matter if the healthcare professionals' opinions will be adopted or not. If the requirement cannot be fulfilled and the modification cannot be done, the hospital must admit the technical limitation. This practice can prevent misunderstanding between the healthcare professionals and the hospital. Lastly, the organizational policies or other decision making on operational strategies in hospital should be more transparent, which could help healthcare professionals to have better understanding on the development of the organization as a whole.

\section{References}

1. van Velthoven MH, Mastellos N, MajeedA, O’Donoghue J, Car J (2016) Feasibility of extracting data from electronic medical records for research: An international comparative study. BMC Medical Informatics and Decision Making 16: 90-100.

2. Cheng TM (2015) Reflections on the 20th anniversary of Taiwan's single-payer
National Health Insurance System. Health Aff (Millwood) 34: 502-510. [Crossref]

3. Chiang JC, Wang TY, Hsu FJ (2014) Factors impacting hospital financial performance in Taiwan following implementation of National Health Insurance. International Business Research 7: 43-52

4. Heart T, Ben-Assuli O, Shabtai I (2017) A review of PHR, EMR and EHR integration: A more personalized healthcare and public health policy. Health Policy and Technology 6: $20-25$.

5. Kim YG, Jung K, Park YT, Shin D, Cho SY, et al. (2017) Rate of electronic health record adoption in South Korea: A nation-wide survey. Int J MedInform 101: 100-107. [Crossref]

6. Kruse CS, Kristof C, Jones B, Mitchell E, Martinez A (2016) Barriers to Electronic Health Record Adoption: A Systematic Literature Review. J Med Syst 40: 252.[Crossref]

7. Mazaheri E, Basil DZ, Yanamandram V, Daroczi Z (2011) The impact of pre-existing attitude and conflict management style on customer satisfaction with service recovery. Journal of Retailing and Consumer Services 18: 235-245.

8. Morrison EW, Robinson SL (1997) When employees feel betrayed: A model of how psychological contract violation develops. Academy of Management Review 22: 226256.

9. Klaus T, Blanton JE (2010)User resistance determinants and the psychological contract in enterprise system implementations. EurJ Inf Syst 19: 625-636.

10. Greenberg J (1993) Stealing in the name of justice: Informational and interpersonal moderators of theft reactions to underpayment inequity. Organizational Behavior and Human Decision Processes 54: 81-103.

11. Nesterkin DA (2013) Organizational change and psychological reactance. Journal of Organizational Change Management 26: 573-594.

12. Rivard S, Lapointe L (2012) Information technology implementers' responses to user resistance: Nature and effects. MIS Quarterly 36: 897-920.

13. Chen YC, Wu JH (2011) IT management capability and its impact on the performance of a CIO. Information \& Management 48: 145-156.

14. Wu JH, Chen YC, Greenes RA (2009) Healthcare technology management competency and its impacts on IT-healthcare partnerships development. Int J Med Inform 78: 71-82. [Crossref]

Copyright: (C2017 Chang HH. This is an open-access article distributed under the terms of the Creative Commons Attribution License, which permits unrestricted use, distribution, and reproduction in any medium, provided the original author and source are credited. 